\title{
The impact of hunger on food cue processing: An event-related brain potential study
}

\author{
Jessica Stockburger, Ralf Schmälzle, Tobias Flaisch, Florian Bublatzky, Harald T. Schupp* \\ Department of Psychology, University of Konstanz, 78457, Germany
}

\section{Keywords:}

Attention

Deprivation

Eating

Motivation

ERP

\begin{abstract}
A B S T R A C T
The present study used event related brain potentials to examine deprivation effects on visual attention to food stimuli at the level of distinct processing stages. Thirty two healthy volunteers (16 females) were tested twice 1 week apart, either after $24 \mathrm{~h}$ of food deprivation or after normal food intake. Participants viewed a continuous stream of food and flower images while dense sensor ERPs were recorded. As revealed by distinct ERP modulations in relatively earlier and later time windows, deprivation affected the processing of food and flower pictures. Between 300 and $360 \mathrm{~ms}$, food pictures were associated with enlarged occipito temporal negativity and centro parietal positivity in deprived compared to satiated state. Of main interest, in a later time window ( $450600 \mathrm{~ms}$ ), deprivation increased amplitudes of the late positive potential elicited by food pictures. Conversely, flower processing varied by motivational state with decreased positive potentials in the deprived state. Minimum Norm analyses provided further evidence that deprivation enhanced visual attention to food cues in later processing stages. From the perspective of motivated attention, hunger may induce a heightened state of attention for food stimuli in a processing stage related to stimulus recognition and focused attention.
\end{abstract}

It is well known that food deprivation has powerful effects on anticipatory and consummatory food related behavior. Acute food deprivation (ranging from $148 \mathrm{~h}$ ) is associated with increased food consumption in animals and humans (Grill and Berridge, 1985; DiBattista, 1987; Spiegel et al., 1989; Hagan and Moss, 1997; Drobes et al., 2001; Mauler et al., 2006). Using behavioral economics and choice paradigms, it was shown that food deprivation enhanced the reinforcing value of food (Bulik and Brinded, 1994; Epstein and Saelens, 2000; Raynor and Epstein, 2003). Food deprivation also increases the attention paid to food stimuli. Research relying on the dot probe task revealed increased selective attention to food words in the deprived state (Mogg et al., 1998; Placanica et al., 2002). Similarly, deprivation delayed the naming of the color of food words in the modified Stroop paradigm (Channon and Hayward, 1990; Lavy and van den Hout, 1993; Dobson and Dozois, 2004). Implicit tests revealed that even modest levels of deprivation $(\sim 2 \mathrm{~h})$ in creased approach tendencies to food words (Seibt et al., 2007). These findings are consistent with the notion of a motivational regulation of attention processes (Lang et al., 1997).

It is a critical challenge to detail motivated attention effects at a more fundamental level. Attention refers to a collection of disparate functional processes operating at various stages of stimulus proces sing (e.g., perception, decision, motor preparation and response), which can be revealed by brain measures (Hillyard et al., 1995; Luck et al., 2000). Functional magnetic resonance imaging (fMRI) provided

* Corresponding author. Institute of Psychology, University of Konstanz, PO Box 36, 78457 Konstanz, Germany. Fax: +49 7531882971.

E-mail address: harald.schupp@uni-konstanz.de (H.T. Schupp). initial evidence that hunger and satiety already affect stimulus perception (Uher et al., 2006; Cheng et al., 2007; Delparigi et al., 2005; Kringelbach et al., 2003; Tataranni et al., 1999; Small et al., 2001; LaBar et al., 2001; Morris and Dolan, 2001). For example, LaBar et al. (2001) observed that food deprivation enhanced the activity in higher order visual associative regions and the amygdala when processing food pictures. These findings are conceptually similar to fMRI studies directing explicit attention toward visual features, objects, and higher order semantic categories, which reveal accen tuated activations in occipital and inferior temporal cortical regions (Kastner and Ungerleider, 2000). Accordingly, it has been proposed that deprivation enhances attention processes to need related food stimuli (LaBar et al., 2001).

Event related brain potentials (ERP) enable the delineation of the time course of visual attention at the level of distinct stages of sti mulus processing. Spatial and object or feature based attention processes are reflected by distinct ERP components. While spatial attention facilitates exogenous P1 ( 80 $120 \mathrm{~ms})$ and N1 ( 140 $190 \mathrm{~ms}$ ) peaks, attention to nonspatial stimulus features is associated with longer latency endogenous ERP components in the $150350 \mathrm{~ms}$ time range, specifically elicited by target stimuli (Hillyard et al., 1995; Hillyard and Anllo Vento, 1998). Emotionally significant stimuli elicit similar ERP modulations as voluntary attention to explicit stimulus characteristics (Schupp et al., 2003). Accordingly, it has been sug gested that implicit emotional or explicit task relevant stimuli are selected for preferential processing in perceptual representation regions (Potts and Tucker, 2001; Sergent et al., 2005; Schupp et al., 2007). A recent study extended these findings to variations in the motivational state of hunger by presenting interspersed food pictures 
in a stream of pleasant, neutral, and unpleasant control pictures (Stockburger et al., 2008). Deprivation specifically modulated the ERP waveform to food stimuli early in the processing stream $(\sim 170$ $300 \mathrm{~ms}$ ). Estimates of the generator sources of the differential ERP activity suggested that hunger enhanced the activity elicited by food pictures in occipito temporo parietal regions. The finding that hunger is able to regulate information processing of need related stimuli during an early processing stage provides the impetus for research investigating neural processing in later processing stages.

It has been consistently observed that explicit task and implicit emotional stimulus relevance is reflected by late positive potentials (LPP) occurring between 300 and $700 \mathrm{~ms}$ after stimulus onset. With regard to explicit tasks, target stimuli defined either by simple physical characteristics or according to higher semantic meaning elicit enlarged LPP amplitudes (Smid et al., 1999; Potts and Tucker, 2001; Delorme et al., 2004; Codispoti et al., 2006). Research using the attentional blink paradigm suggested that the LPP reflects a pro cessing stage linked in part to conscious stimulus recognition, focused attention and elaborate stimulus analysis (Kranczioch et al., 2003; Sergent et al., 2005; Vogel et al., 1998). Regarding implicit stimulus significance, it has been consistently shown that pleasant and unpleasant pictures elicit a pronounced LPP component compared to neutral picture contents (Schupp et al., 2003; Schupp et al., 2007). In the food domain, LPP amplitudes to pictures of meat were larger in vegetarians compared to omnivores (Stockburger et al., 2009). A recent study observed that images showing high fat food items elicited increased activation in multiple cortical generator structures including temporo occipital, inferior parietal, and dorsal prefrontal regions (Toepel et al., 2009). These findings raise the question whether food deprivation modulates later stages of processing similar to the effects of implicit emotional and explicit task significance. Specifically, it is suggested that dynamic shifts in internal motiva tional states enhance visual attention to food pictures, as indexed by the LPP component.

Previous studies revealed that food deprivation effects are specific to need relevant food stimuli. One way to determine specificity is to demonstrate that deprivation had no effects on the processing of neutral stimulus categories, i.e., tools or household objects (LaBar et al., 2001; Morris and Dolan, 2001). Furthermore, the presentation of emotional control materials determined that deprivation effects did not extend to the processing of non food appetitive or aversive stimuli (Lüthy et al., 2003; Drobes et al., 2001; Mauler et al., 2006; Stockburger et al., 2008). Both approaches were implemented in the present study. In the main experimental con dition, deprivation specific effects of food picture processing were assessed using flower pictures as control category. As in previous fMRI studies, control stimuli were drawn from a distinct stimulus category. Furthermore, in a separate control condition, emotional pictures were presented to explore the hypothesis of unspecific deprivation effects on appetitive and aversive processing.

The main goal of the present study was to determine whether food deprivation modulates the processing of food pictures at later stages of processing. As in our previous research (Stockburger et al., 2008), participants passively viewed the stimuli to reveal the obligatory nature of deprivation effects. Selective attention studies observed changes in stimulus perception primarily under conditions of high perceptual load (cf. Luck et al., 2000). Accordingly, in both experimental conditions, picture materials were presented in a continuous stream, in which each picture was shown for $660 \mathrm{~ms}$ Analogous to enhanced LPP amplitudes for emotionally significant stimuli (Cuthbert et al., 2000; Schupp et al., 2006), it was predicted that food deprivation enhances the LPP elicited by food pictures. Regarding earlier deprivation effects, ERP components preceding the LPP were examined (Stockburger et al., 2008). The hypothesis of need specific deprivation effects assumes that enhanced neural processing is specific to food picture processing. Therefore, neither flower nor emotional picture processing was expected to vary as a function of motivational state.

\section{Methods}

\section{Participants}

Participants were 32 healthy volunteers ( 16 women; mean age: 23.3 years, $\mathrm{SD}=3.3$; mean Body Mass Index: $21.6 \mathrm{~kg} / \mathrm{m}^{2}, \mathrm{SD}=1.4$; 29 right handed) from the University of Konstanz. Screening questions related to eating disorders (anorexia, bulimia) and binge eating periods from the diagnostic interview for mental disorders (DIPS; Margraf et al., 1991) served to exclude volunteers with eating disorders. Eating habits were assessed by standardized eating scales (IEG, Diehl and Staufenbiel, 1994; including German adaptations from the TFEQ Stunkard and Messick, 1985). Participants following a vegetarian diet or reporting food allergies were also not included in the study sample. Further exclusion criteria were current use of medication, psychiatric or neurological illness, diabetes mellitus, and regular smoking. All participants provided written informed consent approved by the Review Board of the University of Konstanz. Participants received 20 Euros or course credits for their participation in both experimental sessions.

\section{Stimulus materials}

Food stimuli $(N=40)$ comprised pictures of appetizing main dishes on plates, which were taken from commercially available cookbooks (see Fig. 1). Flower stimuli $(N=40)$ were selected to resemble the food pictures with regard to picture composition (e.g.,

Food
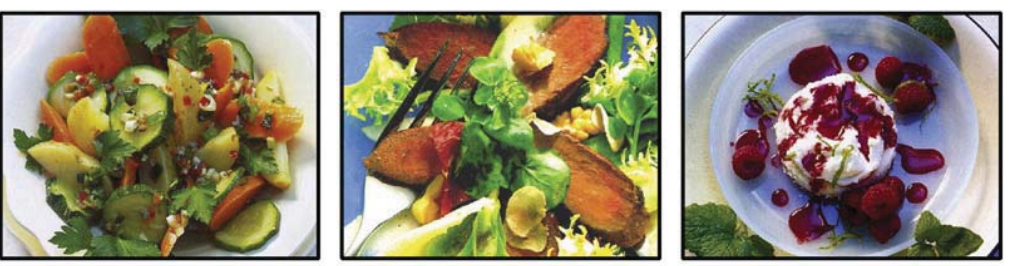

Flower
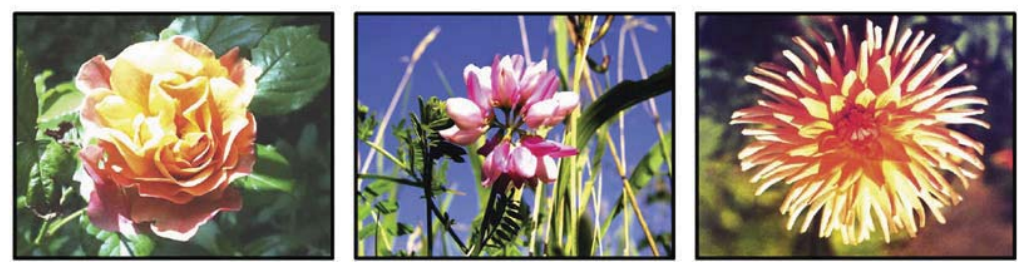

Fig. 1. Representative examples of the food and flower stimuli. 


\section{Deprivation Effects on Food Pictures}

\section{Earlier Time Window}

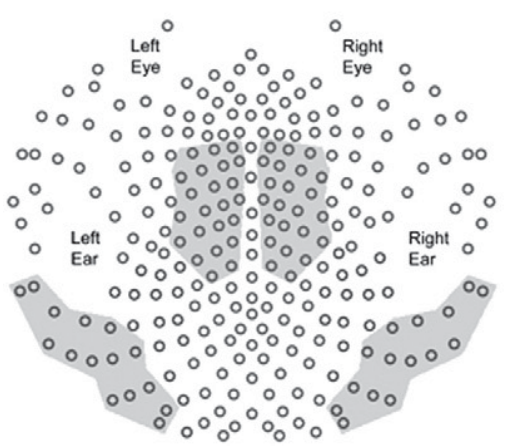

Later Time Window

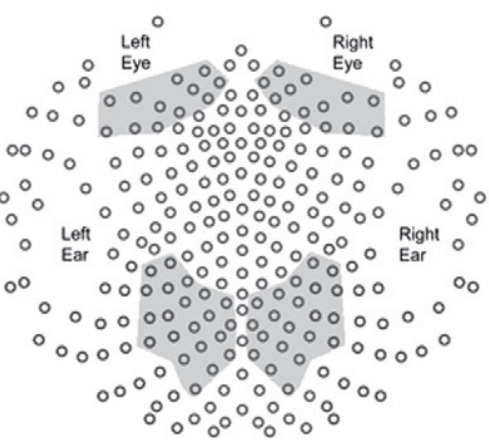

\section{Deprivation Effects on Flower Pictures}

\section{Earlier \& Later Time Windows}

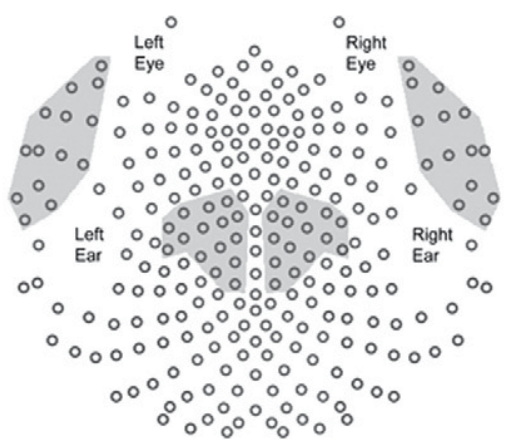

Fig. 2. Illustration of the sensor-montage of the high-density EEG-system. Grey areas indicate sensor clusters included in conventional ANOVA analysis regarding earlier and later deprivation effects on food and flower picture processing, respectively.

stimulus complexity, figure/ground composition). Furthermore, pleasant $(N=40)$, unpleasant $(N=40)$, and neutral $(N=40)$ pictures were selected from the International Affective Picture System (IAPS; Lang et al., 2005) ${ }^{1}$.

\section{Stimulus presentation}

Relying on the rapid serial visual presentation technique, the stimulus materials were presented as a continuous stream without perceivable inter stimulus gap, with each picture shown for $660 \mathrm{~ms}$. The experiment consisted of two experimental conditions, presenting food and flower pictures in one condition and pleasant, neutral, and unpleasant IAPS pictures in another. The order of the two conditions was counter balanced across participants. Assuring a high signal to noise ratio of the ERP, the picture set was repeated 15 and 9 times $(N=1200$ and 1080 trials) in the respective food/flower and IAPS conditions. In both blocks, pictures were shown in random order with no more than three repetitions of the same picture category. Several constraints were imposed on the stimulus order to assure adequate control of sequence effects; the various picture category transitions occurred roughly with the same respective frequencies in both experimental conditions (cf. Flaisch et al., 2008).

\section{Procedure}

An initial screening session served to inform participants of the main conditions of the study and data regarding exclusion criteria were collected. Participants were informed of the requirements for implementing the food deprivation and the normal eating session. Additionally, participants were introduced to the blood sampling procedure, i.e., taking a blood sample from the forefinger of the non dominant hand using cetone sensitive sticks (MediSense Pre cision $\mathrm{Xtra}^{\odot}$ ), which provide an objective measure of compliance with food deprivation (Mauler et al., 2006).

Each participant was tested on two separate days, 1 week apart, either in food deprived or satiated state. The order of these expe rimental sessions was counter balanced. To control for variations in

\footnotetext{
1 IAPS numbers: Pleasant pictures 2070, 1722, 1710, 8400, 8080, 5621, 8510, 4610, 4533, 4561, 4210, 4232, 4611, 4680, 4659, 4810, 2080, 1440, 1540, 8370, 5623, 8161, $8531,4700,4250,4550,4235,4530,4690,4670,4658,4800,1811,2092,2311,2530$, $4641,8040,8210$, and 8496; neutral pictures $7211,7175,7002,7705,7090,7150,7140$, 7089, 7025, 7034, 7217, 7010, 7500, 7560, 7020, 7100, 7190, 7170, 7950, 7224, 7040, 7030, 7130, 7031, 7235, 7110, 7234, 7050, 7510, 7590, 6150, 7060, 2190, 2200, 2383, $2575,5455,7503,7550$, and 8010; unpleasant pictures 1931, 1321, 1302, 1052, 6260, $6350,6250,6510,3120,3110,3064,3130,2900,9001,9140,9220,1930,1300,1301$, $1120,6230,6550,6244,6560,3071,3102,3015,3010,2700,9000,9570,2205,1201$, $3022,3530,6940,9500,9561,9611$, and 9921.
}

circadian rhythm, testing always occurred after lunch time. Prior to the food deprivation session, participants were asked to completely refrain from eating food or drinking sweetened beverages for $24 \mathrm{~h}$. Instructions for the satiated session required participants to follow their normal eating habits and to have a regular lunch. Prior to both testing sessions, participants were requested to record their food and fluid intake by keeping diary and to abstain from drinking alcohol. All participants reported in the interviews that they had complied with the requirements concerning their eating behavior.

For both sessions, self report data regarding hunger and appetite were collected using visual analog scales (range: 19 ). Furthermore, the pictures were evaluated on the dimensions valence and arousal using the Self Assessment Manikin (range: 1 9; Bradley and Lang, 1994).

\section{ERP data collection}

Electrophysiological data were collected from the scalp using a 257 lead geodesic sensor net (EGI: Electrical Geodesics, Inc., Eugene, $\mathrm{OR}$ ). The EEG was recorded continuously with a sampling rate of $250 \mathrm{~Hz}$, with the vertex sensor as reference electrode, and on line filtered from $0.1100 \mathrm{~Hz}$ using Netstation acquisition software and EGI amplifiers. Impedances were kept below $50 \mathrm{k} \Omega$, as recom mended for this type of amplifier by EGI guidelines. Off line analyses were performed using EMEGS (Junghöfer and Peyk, 2004), which included low pass filtering at $40 \mathrm{~Hz}$, artifact detection, sensor interpolation, baseline correction for pre stimulus (40 ms) ERP activity, and conversion to an average reference (Junghöfer et al., 2000). Separate averages were calculated for each picture category (food and flower pictures; pleasant, neutral, and unpleasant IAPS pictures) for the two sessions (hungry and satiated) for each sensor and participant.

\section{Data analysis}

\section{Self report}

Hunger and appetite ratings were analyzed separately using $t$ tests comparing hungry and satiated states. Food and flower picture ratings were analyzed for valence and arousal using repeated measures ANOVAs including factors of State (hungry vs. satiated) and Picture Category (food vs. flower). Analyses of the IAPS picture ratings comprised the factors State (hungry vs. satiated) and Picture Category (pleasant vs. neutral vs. unpleasant).

\section{ERP analyses: food vs. flower picture processing}

To determine food deprivation effects on the processing of food and flower pictures, ERP waveform analyses were used in concert 
with conventional ANOVA analyses based on area scores, i.e., mean activity in selected sensor regions and time windows.

Waveform analyses. To determine deprivation effects on food and flower pictures, ERP waveform analyses were conducted. Specifically, each sensor was tested separately in repeated measures ANOVAs, including factors of State (hungry vs. satiated) and Picture Category (food vs. flower). To guard against chance findings, these analyses were based on $48 \mathrm{~ms}$ time bins and significant effects were only considered meaningful when the effects were observed for at least two neighboring sensors (cf. Sabbagh and Taylor, 2000). Waveform analyses served to determine time course and topographical distribution of the interaction State $\times$ Picture Category. Pronounced interaction effects of State and Picture Category emerged between 300 and $600 \mathrm{~ms}$ after stimulus onset. Accordingly, separate waveform analyses were conducted for food and flower pictures in this time window.

Area score analyses. Subsequently, area scores were analyzed in ANOVA analyses to examine the interaction of motivational State and Picture Category and to determine the specificity of the deprivation effects on the respective food and flower pictures. With regard to food picture processing, deprivation effects changed both in terms of polarity and topography in relatively earlier (300 $360 \mathrm{~ms}$ ) and later (450 $600 \mathrm{~ms}$ ) time windows. As shown in Fig. 2, separate sensor clusters were defined for relatively earlier and later time windows based on waveform analyses and visual inspection. By contrast, deprivation effects of flower pictures were observed with the same polarity and stable topography and were analyzed in two correspond ing sensor clusters (see Fig. 2). Specificity of deprivation effects predicts a significant interaction of State $\times$ Picture Category $\times$ Location of the sensor clusters.

Earlier and later deprivation effects on food picture processing appeared with different topographies. Accordingly, in a further analysis, earlier and later food specific sensor clusters were analyzed and a significant interaction of State $\times$ Location was predicted.

Baseline control analyses. In rapid serial picture presentations, systematic ERP differences during the pre stimulus 'baseline' interval need to be considered (cf. Flaisch et al., 2008). To prevent systematic differences in ERP activity at the time of picture presentation, stimulus transitions were controlled. Furthermore, waveform analyses were conducted based on the $40 \mathrm{~ms}$ baseline interval. Neither state dependent differences for food or flower pictures nor systematic differences due to picture category were revealed by these baseline control analyses. These analyses confirmed that the present effects are not due to residual brain activity associated with the processing of the preceding picture.

\section{ERP analyses: IAPS picture processing}

To replicate previous findings of selective emotion processing and to explore effects of food deprivation on emotion processing, the early posterior negativity (EPN) was scored in bilateral temporo occipital clusters ${ }^{2}$ in a time window from $200300 \mathrm{~ms}$ (cf. Schupp et al., 2007). The late positive potential (LPP) was scored in bilateral centro medial clusters ${ }^{3}$ in a time window from 400600 ms (cf. Schupp et al., 2007; Flaisch et al., 2008). Data were entered into ANOVAs that included the factors State (hungry vs. satiated), Picture Category (pleasant vs. neutral vs. unpleasant),

2 EGI sensor numbers (EPN): 93, 94, 95, 96, 104, 105, 106, 107, 108, 112, 113, 114, 115 116, 117, 121, 122, 123, 124, 125, 134, 135, 136, 146, 147 (left); 149, 450, 151, 152, 157, 158 $159,160,161,162,166,167,168,169,170,171,175,176,177,178,179,188,189,190,191$ 200 (right).

${ }^{3}$ EGI sensor numbers (LPP): 9, 16, 17, 23, 24, 29, 41, 42, 43, 44, 51, 52, 79 (left); 6, 7, $132,133,145,185,186,187,198,199,207,208,216$ (right).

\section{A Manipulation Check}
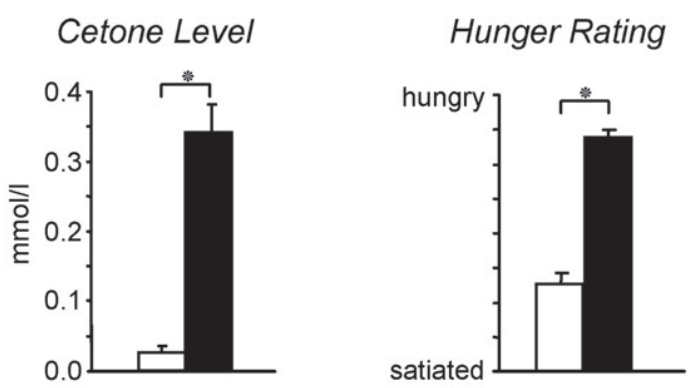

B

Picture Evaluation

Valence

Arousal
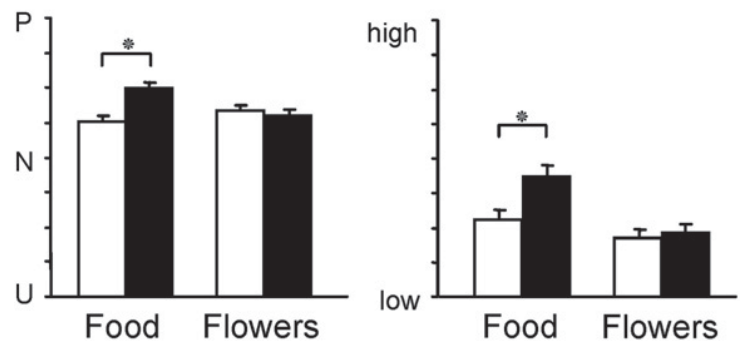

SAT HUN

Fig. 3. (A) Left and right panels illustrate the mean cetone level and hunger ratings in the hungry (HUN) and satiated (SAT) states, respectively. (B) Left and right panels show mean valence and arousal ratings for food and flower pictures in the hungry and satiated states.

and Laterality (left vs. right). Furthermore, sensor clusters evincing relatively earlier and later deprivation effects on food and flower pictures were also analyzed for deprivation effects on IAPS pictures.

Further control analyses explored IAPS picture processing in sensor clusters which revealed deprivation effects on food and flower processing. These sensor clusters revealed no significant main effects of State or higher order interactions involving State with regard to earlier and later time windows.

When appropriate, the Greenhouse Geisser procedure was used to correct for violations of sphericity.

\section{Results}

\section{Deprivation manipulation check}

As shown in Fig. 3A, cetone levels increased significantly in the hungry state $(M=0.34 \mathrm{mmol} / \mathrm{l}, \mathrm{SD}=0.2)$, as compared to the satiated session $(M=0.03 \mathrm{mmol} / \mathrm{l}, \mathrm{SD}=0.05), t(30)=7.4, p<0.0001$. Addi tionally, when compared to satiated state, self reported hunger and appetite increased in the deprived state, $t s(31)=14.0$ and 13.0, $p<0.001$, respectively.

Picture ratings

\section{Food and flower pictures}

Deprivation differentially modulated pleasantness ratings of food and flower pictures, State $\times$ Picture Category, $F(1,31)=26.5, p<0.001$ (see Fig. 3B). When food deprived, participants rated the food pictures as significantly more pleasant, as compared to the satiated state, $t(31)=6.1, p<0.001$. By contrast, pleasantness ratings of flower pictures were not modulated under deprivation, as compared to satiety, $t(31)=1.0$, ns. 
Table 1

Valence and arousal ratings as a function of picture category and motivational state (standard deviations in parentheses).

\begin{tabular}{llcr}
\hline & & \multicolumn{1}{l}{ Satiated } & \multicolumn{1}{l}{ Hungry } \\
\hline Valence & Pleasant & $6.91(0.88)$ & $6.79(0.85)$ \\
& Neutral & $5.13(0.31)$ & $5.11(0.30)$ \\
Arousal & Unpleasant & $2.75(0.54)$ & $2.92(0.53)$ \\
& Pleasant & $4.34(1.72)$ & $4.31(1.72)$ \\
& Neutral & $2.59(1.19)$ & $2.72(1.36)$ \\
& Unpleasant & $5.35(1.69)$ & $5.25(1.77)$ \\
EPN & & & \\
& Pleasant & $0.47(0.14)$ & $0.28(0.16)$ \\
& Neutral & $1.78(0.18)$ & $1.64(0.20)$ \\
LPP & Unpleasant & $0.40(0.14)$ & $0.25(0.16)$ \\
& Pleasant & $0.30(0.11)$ & $0.30(0.12)$ \\
& Neutral & $1.39(0.14)$ & $1.54(0.17)$ \\
& Unpleasant & $0.31(0.12)$ & $0.45(0.15)$ \\
\hline
\end{tabular}

EPN and LPP mean amplitudes for IAPS stimuli for the satiated and hungry states (standard deviations in parentheses).

Regarding arousal ratings, food pictures were perceived as more arousing than flower pictures, Picture Category, $F(1,31)=41.4$, $p<0.001$ (see Fig. 3B). Moreover, similar to the valence ratings, deprivation effects varied across picture materials, State $\times$ Picture Category, $F(1,31)=26.5, p<0.001$. When food deprived, participants rated the food pictures as significantly more arousing compared to the satiated state, $t(31)=6.1, p<0.001$, while flower ratings did not vary as a function of motivational state, $t(31)=0.7$, ns.

\section{IAPS pictures}

As in previous research, ratings of pleasant, neutral, and unpleasant pictures significantly varied in valence, Picture Category,
$F(2,62)=337.3, p<0.001$. In addition, a significant interaction of State $\times$ Picture Category was observed, $F(2,62)=6.5, p<0.01$. Follow up tests revealed that unpleasant pictures were perceived as less aversive when participants were hungry, $t(31)=2.9, p<0.01$, (see Table 1). Arousal ratings replicated previous findings in that pleasant and unpleasant pictures were evaluated as more arousing than neutral stimuli, Picture Category, $F(2,62)=102.9, p<0.001$. Depriva tion did not systematically modulate arousal ratings, $F s<1.5$, ns.

\section{ERP analyses: food vs. flower picture processing}

\section{Waveform analyses}

As shown in Figs. 4 and 5, pronounced differences emerged as a function of Picture Category. Compared to flower pictures, food cues were associated with increased positivity over posterior sites developing around $6070 \mathrm{~ms}$ post stimulus and lasting until $300 \mathrm{~ms}$ (see Fig. 4A). Subsequently, the pattern of increased positivity over occipito parieto temporal sites shifted toward par ieto central locations and a pronounced corresponding negativity was observed over frontal and inferior temporal sensor sites.

Of main interest, the overall analysis revealed significant interac tions of State $\times$ Picture Category in a time window from $300600 \mathrm{~ms}$ after picture presentation (see Fig. 4B). Accordingly, separate wave form analyses were calculated for food and flower picture categories. As shown in Fig. 6A, deprivation modulated the processing of food pictures in two time periods. In a time interval from $300350 \mathrm{~ms}$, food pictures elicited a relative negative potential at occipito temporal sensor locations (more pronounced on the left side, see Fig. 5A) and a relative positive potential over centro frontal locations when viewed under deprivation as opposed to satiety. Subsequently, deprivation
A

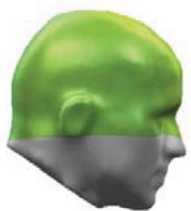

$0-100$

B
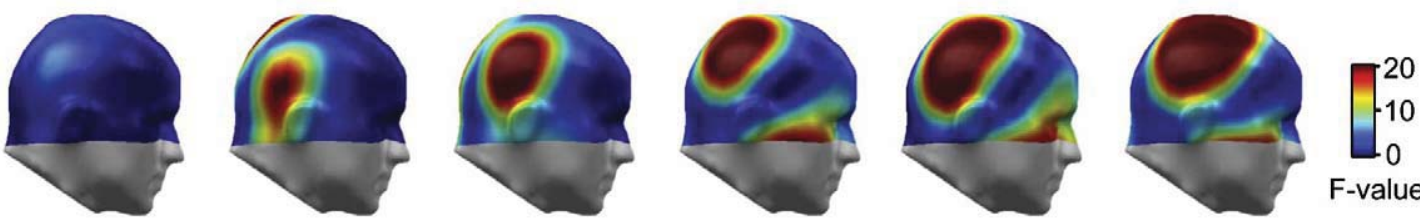

Interaction: State x Picture Category
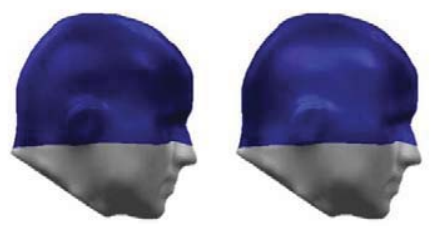

$0-100$

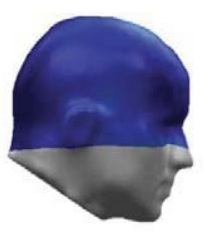

200-300

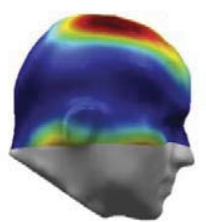

$300-400$

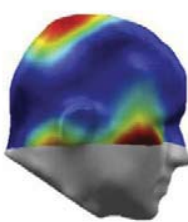

$400-500$

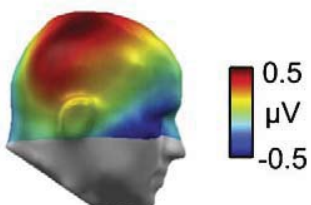

$500-600$

Time $[\mathrm{ms}]$

Fig. 4. (A) Collapsing across $100 \mathrm{~ms}$ time bins, the topographical distribution of the scalp difference potentials (food-flower pictures) are illustrated. (B) Based on the waveform analysis, main effects of Picture Category and the interaction of State $\times$ Picture Category are illustrated. F-values greater than 4.1 reflect significant effects $(p<0.05)$. A right view of a model head is shown. 

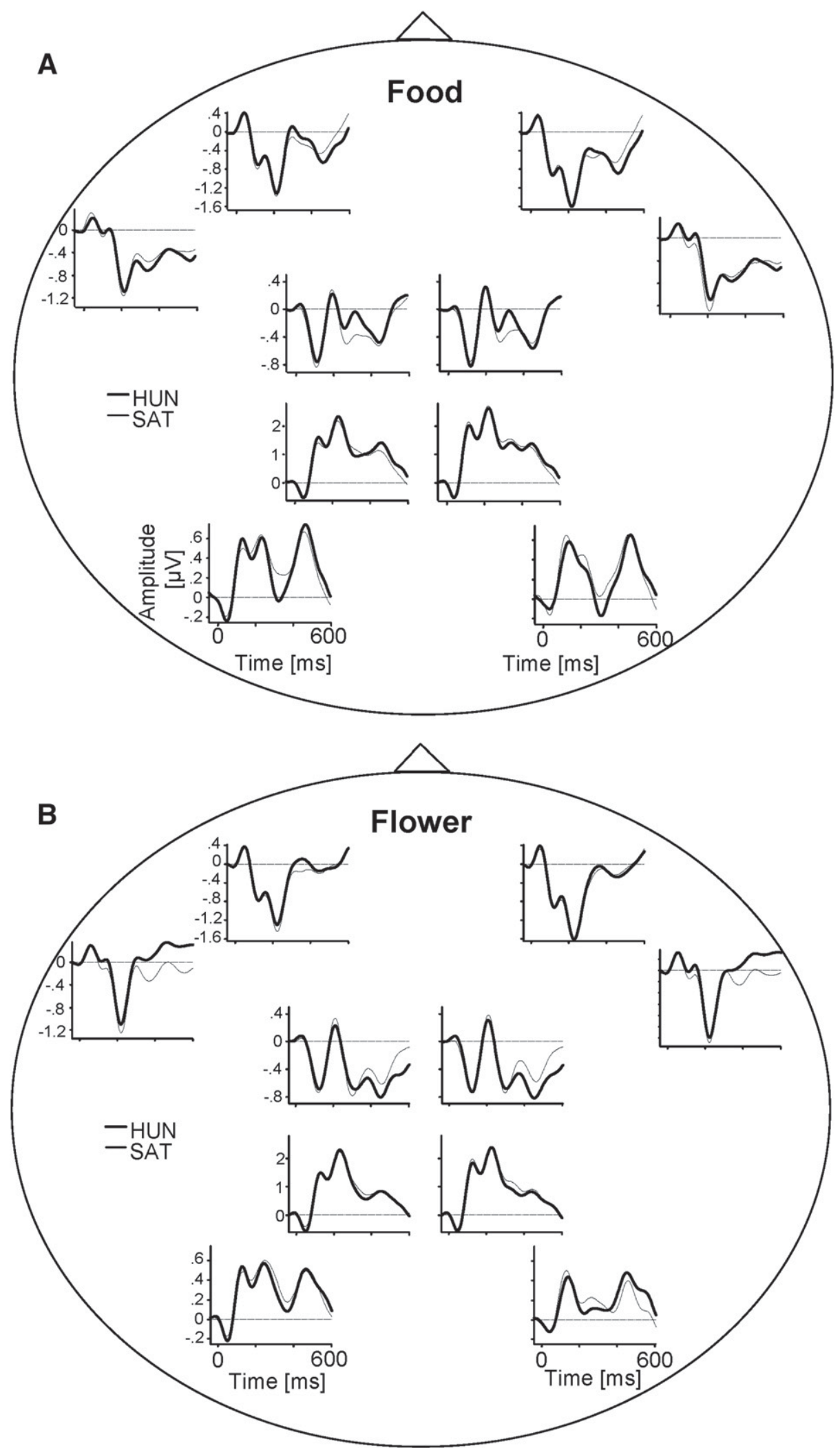

Fig. 5. (A) Representative ERP-waveforms for food pictures in the hungry (thick lines) and satiated (thin lines) states. (B) Representative ERP-waveforms for flower pictures in the hungry (thick lines) and satiated (thin lines) states.

effects on food picture processing appeared between $450600 \mathrm{~ms}$ as a relative positive potential over parietal sensors and a corresponding polarity reversal at frontal locations. As shown in Fig. 6B, contrasting deprivation effects emerged when analyzing flower pictures with regard to topography and polarity. Specifically, deprivation effects appeared as increased negativity over centro parietal locations and corresponding positivity at fronto temporal regions in a time window lasting from $300600 \mathrm{~ms}$ after stimulus onset. 
Area score: 'earlier' deprivation effects (300 $600 \mathrm{~ms}$ )

To determine the specificity of food deprivation on food and flower processing, the four sensor regions sensitive to deprivation were submitted to an overall ANOVA analysis containing the factors of State (hungry vs. satiated), Picture Category (food vs. flower), Location (occipito temporal vs. centro frontal vs. centro parietal vs. fronto temporal), and Laterality (left vs. right). A significant higher order interaction of State $\times$ Picture Category $\times$ Location was observed, $F(3,93)=8.1, p<0.001$. Accordingly, follow up ANOVAs were ana lyzed to determine earlier deprivation effects for each sensor cluster separately.

Occipito temporal sensor clusters. Food pictures revealed a signifi cantly enhanced negativity in the deprived state as compared to the satiated state, $F(1,31)=5.7, p<0.05$. By contrast, there was no significant deprivation effect on flower pictures, $F(1,31)<1$, ns, and the higher order interaction State $\times$ Picture Category reached signifi cance, $F(1,31)=4.5, p<0.05$.

Centro frontal sensor clusters. Food pictures elicited an increased positivity in the deprived state as compared to the satiated state, $F(1,31)=7.8, p<0.05$. Conversely, no significant deprivation effect appeared for flower pictures, $F(1,31)<1$, ns, State $\times$ Picture Category, $F(1,31)=7.9, p<0.01$

Centro parietal sensor clusters. In this cluster, deprivation effects were observed for flower pictures, associated with an increased negativity in the deprived state as opposed to the satiated state, $F$ $(1,31)=4.2, p<0.05$. Effects were specific to flower pictures, for there were no significant deprivation effects on food pictures, $F$ $(1,31)<1.7$, ns, State $\times$ Picture Category, $F(1,31)=7.1, p<0.05$.

Fronto temporal sensor clusters. Flower pictures were associated with an increased positivity in the deprived state as compared to satiated state, $F(1,31)=5.5, p<0.05$. Processing of food pictures was not modulated by deprivation, $F(1,31)=2.2, p=0.15$, State $\times$ Picture Category, $F(1,31)=10.4, p<0.01$.

\section{Area score: 'later' deprivation effects (450 $600 \mathrm{~ms}$ )}

Conventional ANOVA analyses were conducted to determine the specificity of deprivation effects on food and flower pictures. The four sensor regions showing significant deprivation effects in the food and flower waveform analyses were submitted to an ANOVA analysis containing factors of State (hungry vs. satiated), Picture Category (food vs. flower), Location (parietal vs. frontal vs. centro parietal vs. fronto temporal), and Laterality (left vs. right). The significant higher order interaction of State $\times$ Picture Category $\times$ Location justified the separate analysis of each sensor cluster, $F(3,93)=12.4, p<0.001$, and subsequent analyses confirmed that the observed deprivation effects for food as well as flower pictures were specific to these stimulus materials.

Parietal sensor clusters. Compared to the satiated state, food pic tures revealed a significantly enhanced positivity in the deprived state, $F(1,31)=5.8, p<0.05$. By contrast, there was no significant deprivation effect on flower pictures, $F(1,31)<1$, ns, State $\times$ Picture Category, $F(1,31)=9.8, p<0.01$.

Frontal sensor clusters. Food pictures elicited an increased negativity in the deprived state as compared to the satiated state, $F(1,31)=8.6$, $p<0.05$. By contrast, processing of flower pictures was not modulated by deprivation, $F(1,31)<1$, ns, State $\times$ Picture Category, $F(1,31)=7.3$, $p<0.01$.

Centro parietal sensor clusters. In this cluster, deprivation effects were observed for flower pictures, associated with an increased negativity in the deprived state as compared to the satiated state, $F$ $(1,31)=12.1, p<0.05$. By contrast, there was no significant deprivation effect on food pictures, $F(1,31)=1.5$, ns, State $\times$ Picture Category, $F(1,31)=15.4, p<0.01$.

Fronto temporal sensor clusters. Flower pictures were associated with an increased positivity contrasting deprived and satiated state, $F(1,31)=16.5, \quad p<0.01$. By contrast, processing of food pictures was not modulated by deprivation, $F(1,31)=1.5$, ns, State $\times$ Picture Category, $F(1,31)=16.8, p<0.01$.

Area score: topography changes of deprivation effects on food picture processing

Inspection of Fig. 6A shows that deprivation effects on food processing changed the topography across processing time. To assess the significance of these topography changes, the sensor regions showing relatively earlier and later deprivation effects were analyzed in an overall ANOVA analysis which comprised the factors State (hungry vs. satiated), Picture Category (food vs. flower), Location (occipito temporal vs. centro frontal vs. parietal vs. frontal), and $L a$ terality (left vs. right). As expected, for earlier and later time windows, higher order interactions of State $\times$ Picture Category $\times$ Loca tion were obtained, $F s(3,93)=3.5$ and $5.8, p<0.5$, respectively. Follow up tests for each sensor region revealed that earlier and later deprivation effects were specific to their respective time window, $F \mathrm{~s}<3.1$, ns.

\section{L2 Minimum Norm analysis}

L2 Minimum Norm solutions were calculated to provide an estimate of the generator sources of the deprivation effects on food and flower picture processing. The L2 Minimum Norm estimate enables enhanced resolution of brain activations generating the scalp recorded field potentials without a priori assumptions regarding the location and number of current sources (Hämäläinen and Ilmoniemi, 1994). Calculation of the L2 Minimum Norm was based on a four shell spherical head model with evenly distributed 3 (radial, azimuthal and polar direction) $\times 197$ dipoles as source model. A shell radius of $6 \mathrm{~cm}$ was chosen as the best tradeoff between depth sensitivity and spatial resolution (Hauk, 2004). As shown in Fig. 7B, specific deprivation effects emerged for food picture processing. Con trasting food processing in the hungry and satiated states, deprivation increased dipole strength over extended posterior visual processing regions. Moreover, considering the difference in food and flower processing, anterior brain structures, possibly implicated in the attentional regulation of activity in posterior brain regions (cf. Posner and Petersen, 1990), are differentially recruited in the deprived state as compared to the satiated state.

\section{ERP analyses: IAPS picture processing}

\section{Early posterior negativity}

Replicating previous findings, a significant main effect of Picture Category was observed, $F(2,62)=82.3, p<0.0001$. Pleasant and unpleasant, as compared to neutral pictures elicited a more pro nounced posterior negativity, $F s(1,31)=104.2$ and $79.9, p<0.0001$, respectively. Motivational state did not significantly modulate emo tional picture processing, State, $F(1,31)=2.2$, ns; the interaction of State $\times$ Picture Category was not significant, $F(2,62)<1$, ns.

\section{Late positive potential}

Replicating previous findings, pleasant and unpleasant, as com pared to neutral pictures elicited more pronounced late positive potentials, $F s(1,31)=137.3$ and $118.8, p<0.0001$, respectively; Picture Category, $F(2,62)=106.4, p<0.0001$. Again, no significant main effect 
A
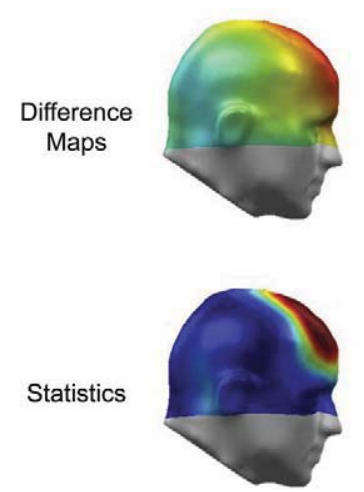

300-350

B
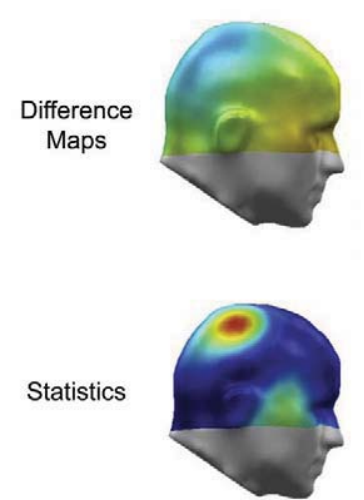

300-350
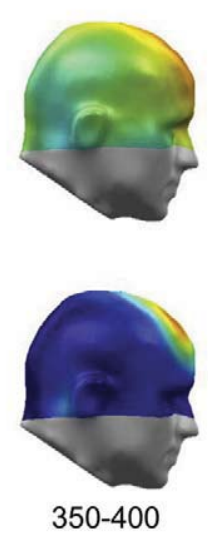

$350-400$
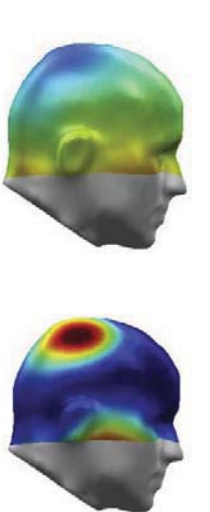

$350-400$
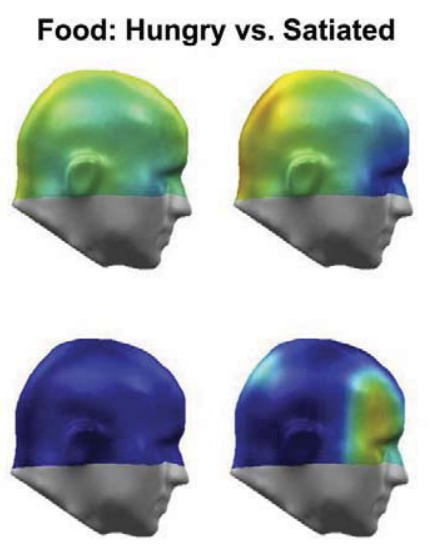

400-450

Time [ms]

450-500

\section{Flowers: Hungry vs. Satiated}
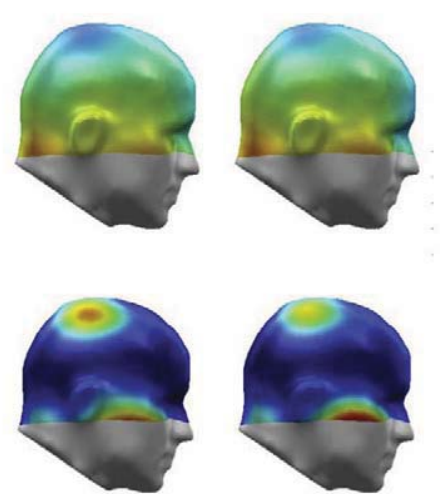

400-450

450-500

Time $[\mathrm{ms}]$
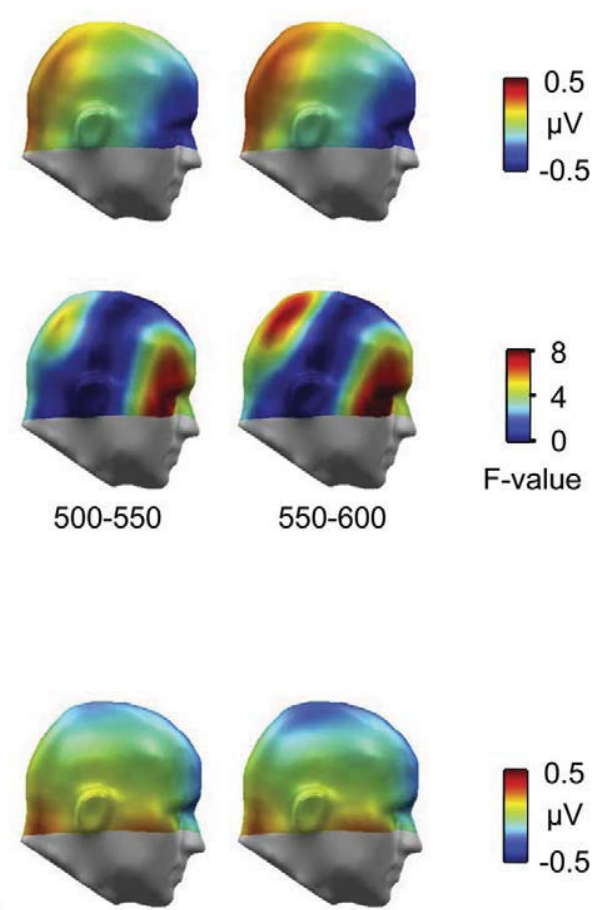

500-550

550-600

F-value
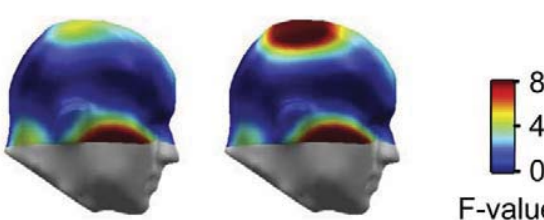

F-value

500-550

Fig. 6. Collapsing across $50 \mathrm{~ms}$ time bins, scalp difference maps (hungry-satiated) and $F$-values of the main effect State are illustrated in a time window from $300--600 \mathrm{~ms}$ for food (A) and flower (B) pictures, respectively. F-values greater than 4.1 reflect significant effects $(p<0.05)$. A right view of a model head is shown.

or higher order interaction including the factor State was observed, Fs $<1.5$, ns.

\section{Discussion}

The present study used event related brain potentials to examine the effects of food deprivation on visual attention to food stimuli at the level of distinct processing stages. The novel finding is that hunger enhanced late positive potentials to food pictures. It is pro posed that food stimuli undergo enhanced processing in a stage related to stimulus recognition and focused attention. In order to implement appropriate behaviors to restore energy levels, food related stimuli need to become the focus of attention. From this perspective, the dynamic need related regulation of attention processes appears highly adaptive.

\section{Food deprivation effects: late positive potentials}

The main finding of the present study is that food deprivation increased attention paid to food cues in a later stage of processing indexed by the LPP. The LPP component has been a prominent measure in ERP research investigating the notion that emotionally and motivationally relevant stimuli induce a natural state of selective attention. A large body of evidence demonstrates that the processing of pictures of erotica, mutilation and threat is associated with enlarged LPP amplitudes, as compared to neutral stimulus contents (reviewed in Schupp et al., 2006). The present study extends these findings, revealing that variations in motivational state enhance visual attention processes at this stage of stimulus processing.

The assumption that increased positive potentials to food pictures in a hungry state reflects enhanced processing is supported by Minimum Norm Source Estimation analyses, which revealed increased dipole strength over extended posterior visual processing regions. These findings are consistent with previous research showing that the LPP reflects the activation of a highly distributed network with key nodes in inferior frontal, posterior parietal, anterior temporal, and occipito temporal regions. Thus, rather than reflecting local or modular processing, the LPP is linked to widespread activation broadcasting stimulus information to many associative cortical regions (Nieuwenhuis et al., 2005; Sergent et al., 2005; Del Cul et al., 2007; Schupp et al., 2007). From a functional perspective, the LPP component has been related to processes of stimulus recognition, working memory representation and focused attention. For example, attentional blink and masking studies demonstrate that the P3 amplitude systematically varied with conscious recognition (Vogel et al., 1998; Sergent et al., 2005; Kranczioch et al., 2003; Del Cul et al., 2007). Specifically, seen target stimuli (presented in the attentional blink interval) elicited a late positive wave, which was absent for unseen target stimuli (Kranczioch et al., 2003; Sergent et al., 2005). Furthermore, increasing task priority in dual task studies led to increased LPPs 
A

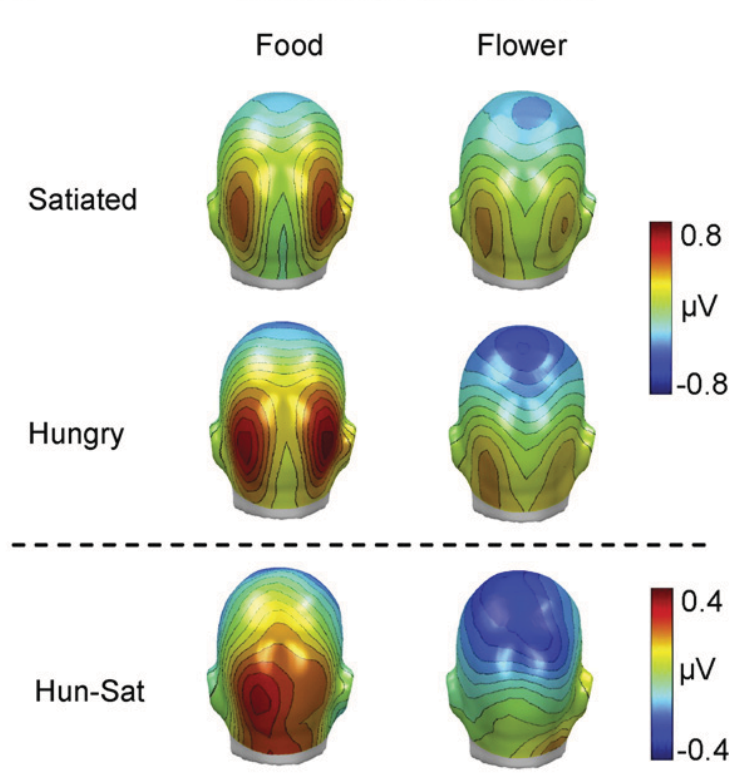

B

\section{L2-MN-Estimations (450-600 ms)}

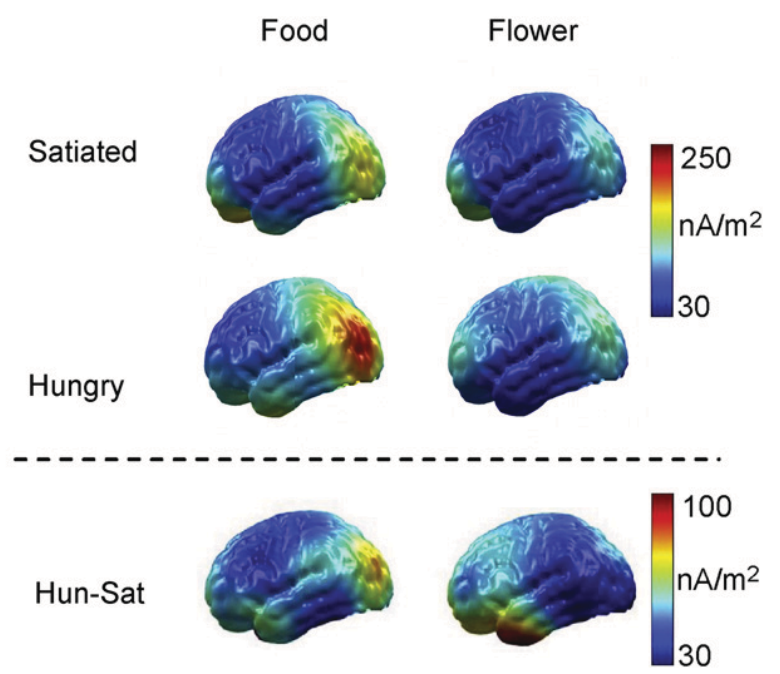

Fig. 7. (A) Scalp potential maps show the topography of the LPP component for food and flower pictures and the difference between the hungry and satiated states. The back view of a model head is illustrated. (B) L2-Minimum-Norm estimates for food and flower pictures and the difference between the hungry and satiated states.

in the primary task and corresponding decreases in secondary task LPP amplitudes (Sirevaag et al., 1989). Based on these findings, it is proposed that deprivation facilitates the processing of need related food cues in a processing stage implicated in stimulus recognition, working memory representation and focused attention.

Interestingly, conceptually similar findings emerged in recent neuroimaging studies examining the processing of food items varying in affective salience and nutritional value. For example, fMRI studies revealed reliable differences in the activation of perceptual and reward related brain regions when comparing high and low caloric food pictures (Killgore et al., 2003). Furthermore, a previous PET study revealed increased parietal activations in obese women when looking at food after an over fasting period (Karhunen et al., 1997). In addition, ERP research indicates that posterior brain regions are differentially engaged in a time window between 300 $600 \mathrm{~ms}$, similar to the current findings. For example, differential inferior parietal and temporo occipital activations have been reported when comparing pictures depicting high fat food items, as compared to low fat ones (Toepel et al., 2009) and a recent study showed that parietal LPP amplitudes to pictures of meat varied as a function of affective salience in vegetarians, as opposed to omnivores (Stockburger et al., 2009). Collectively, these studies suggest that a cortical network involving parieto temporo occipital regions is engaged differentially by salient food stimuli, reflecting enhanced processing during stimulus perception. Extending these findings, the present results showed that variations in internal motivational state may engage a similar posterior cortical network.

Food deprivation effects were also apparent when considering the processing of flower pictures. Interestingly, deprivation exerted converse effects on the processing of food and flower control pictures. The amplitude of the LPP elicited by flower pictures was reduced in the food deprived state. Speculatively, these findings may relate to the issue that attention operates by enhancing or inhibiting stimulus representations. Using spatial attention paradigms, previous beha vioral and fMRI studies suggested suppressive effects of attention (Hillyard and Anllo Vento, 1998; Kanwisher and Wojciulik, 2000). Analogously, attenuated LPP amplitudes to flower pictures in hungry state may indicate suppressive effects of attention. This effect appeared specific to the condition including the presentation of need relevant food pictures, as IAPS pictures were not modulated by food deprivation. Overall, flower pictures were less effective in capturing processing resources in the deprived state when presented in a rapid serial stream containing need relevant food pictures.

In addition to the opposite effects of deprivation on LPP amplitude, sensor clusters evincing deprivation effects differed in the topography for food and flower pictures. One interpretation of these findings is that the motivational regulation of attention is expressed in different visual associative brain regions. Consistent with this notion, pronounced category differences between food and flower pictures were observed. Furthermore, fMRI studies observed different activation patterns in higher order visual associative regions for food pictures, as compared to various control stimuli (e.g., tools, household objects or buildings; LaBar et al., 2001; Morris and Dolan, 2001; Simmons et al., 2005; Rothemund et al., 2007; Stoeckel et al., 2008). Pending on more conclusive evidence, it is suggested that differences in the topography of deprivation effects for food and flower pictures relate to distinct category specific repre sentations in visual associative brain regions (Downing et al., 2001; Schwarzlose et al., 2005).

\section{'Earlier' ERP deprivation effects}

Preceding the LPP, a transitory ERP component was sensitive to food deprivation. Food pictures elicited a more pronounced occipito temporal negativity and central positivity when viewed in a food deprived state. The effect was specific to food pictures and appeared with a distinct topography, as opposed to the later deprivation effects on food picture processing. A similar pattern of anterior and pos terior ERP modulations is often seen in studies of explicit attention and emotional stimulus processing, occurring in a time window between 150350 ms (Smid et al., 1999; Potts \& Tucker, 2001; Codispoti et al., 2006; Junghöfer et al., 2001; Schupp et al., 2003). Conceivably, these relatively earlier ERP deprivation effects may reflect an increased sensitivity to food cues during processing stages gating stimulus recognition, focused attention, and elaborate processing (Schupp et al., 2006).

In the present study, deprivation effects on food pictures appeared considerably later (310 vs. $170 \mathrm{~ms}$ ) than in a previous study (Stockburger et al., 2008). These latency differences may indicate that previous findings of 'early' deprivation effects were not replicated by the present study or that they were secondary to procedural differences. Speed of presentation was slower in the 
present study (660 vs. $330 \mathrm{~ms}$ ) and the contents displayed by the control pictures (flower vs. pleasant, neutral, and unpleasant IAPS pictures) were different. Differences in stimulus discrimination and perceptual demand have a pronounced influence on ERP effects in explicit attention studies (Hillyard and Anllo Vento, 1998; Smid et al., 1999; Luck et al., 2000). Overall, to conclusively resolve the issue regarding earlier deprivation effects, future research that system atically varies control stimulus categories and stimulus presentation rate is needed.

\section{Food deprivation and the concept of motivated attention}

It has been suggested that in natural environments attention is primarily driven by motivation. Rather than treating attention as a rational, cognitive activity, attention is steered according to motiva tional states (Lang et al., 1997). The selective responding and evaluation of need relevant stimuli seems critical to the organization of food related behaviors. Specifically, attention to food cues may elicit approach and anticipatory behaviors (Seibt et al., 2007), increase the willingness to work for food (Epstein and Saelens, 2000; Raynor and Epstein, 2003), or result in heightened food consumption (Mauler et al., 2006), depending on specific environ mental circumstances and affordances (Timberlake, 2001). The present findings extend this framework by delineating the time course of attention operation. Specifically, facilitated processing during perceptual encoding may carry over to later processes including decision and response stages. Regarding food deprivation, previous fMRI studies observed that food related stimuli receive enhanced processing in sensory specific brain regions examining olfactory, gustatory, and visual stimuli (Tataranni et al., 1999; LaBar et al., 2001; Morris and Dolan, 2001; Delparigi et al., 2005; Uher et al., 2006; Cheng et al., 2007). However, while fMRI is excellent in assessing neural structures, the temporal resolution is not sufficient to resolve the dynamics of visual attention to food cues. The present findings demonstrate the motivational regulation of stimulus proces sing in processing stages which presumably act as a gateway to stimulus representation in working memory and focused attention. Moreover, these findings were observed while participants passively viewed the stimulus materials and the food images were not task relevant. Consequently, the motivational regulation of visual proces sing appears to be a spontaneous and involuntary phenomenon, considered as important characteristics of automatic processes (Bargh, 1997). Animal research suggests that the effects of food deprivation may vary as a function of palatability (Barbano and Cador, $2005,2006)$. Given that the present study presented highly appetiz ing food stimuli, future research needs to determine whether similar effects of food deprivation emerge for pictures showing less and highly palatable food.

From a functional perspective, increasing the sensitivity to food stimuli in the deprived state may serve as a highly functional mecha nism that is important to the organization of food related behaviors needed to restore depleted energy levels. However, depending on the circumstances, the motivational regulation of attention may have unwanted consequences when considering chronic effects. In Western societies, an increasing number of individuals are engaged in chronic or sporadic food deprivation and food restriction and restrained eating is common in eating pathology to control body weight (Herman and Polivy, 1980; Bulik and Brinded, 1994; Hetherington et al., 2000). Possibly, the effect of enhanced attention to food cues in the food deprived state is potentiated for individuals with a history of dieting, restrained eating and specific food restric tions. As a result, self control efforts may be undermined by the automatic attention capture of food cues (Logue and King, 1991; Mauler et al., 2006). These considerations suggest to assess deprivation effects on food stimulus processing in relation to restrained eating (Hoefling and Strack, 2008) and at the level of specific food products (e.g., high calorie foods; Killgore et al., 2003; Siep et al., 2008).

\section{Conclusion}

The present findings demonstrate the motivational regulation of attention at the level of distinct processing stages. It is proposed that food deprivation enhances perceptual processing of food stimuli related to a fleeting processing stage, which acts as a gateway for focused attention and stimulus representation in working memory. Moreover, the motivational regulation of attention shows features of automaticity (i.e., spontaneous and involuntary). Presumably reflecting evolutionary heritage, such a mechanism seems highly adaptive by increasing the chances to restore depleted energy stores.

\section{References}

Barbano, M.F., Cador, M., 2005. Various aspects of feeding behavior can be partially dissociated in the rat by the incentive properties of food and the physiological state. Behav. Neurosci. 119, 1244-1253.

Barbano, M.F., Cador, M., 2006. Differential regulation of the consummatory, motivational and anticipatory aspects of feeding behavior by dopaminergic and opioidergic drugs. Neuropsychopharmacology 31, 1371-1381.

Bargh, J.A., 1997. The automaticity of everyday life. In: Wyer, J.R.S. (Ed.), The Automaticity of Everyday Life: Advances in Social Cognition. Erlbaum, Mahwah, NJ, pp. 1-61.

Bradley, M.M., Lang, P.J., 1994. Measuring emotion: the self-assessment manikin and the semantic differential. J. Behav. Ther. Exp. Psychiatry 25, 49-59.

Bulik, C.M., Brinded, E.C. 1994. The effect of food deprivation on the reinforcing value of food and smoking in bulimic and control women. Physiol. Behav. 55, 665-672.

Channon, S., Hayward, A., 1990. The effect of short-term fasting on processing of food cues in normal subjects. Int. J. Eat. Disord. 9, 447-452.

Cheng, Y., Meltzoff, A.N., Decety, J., 2007. Motivation modulates the activity of the human mirror-neuron system. Cereb. Cortex 17, 1979-1986.

Codispoti, M., Ferrari, V., De Cesarei, A., Cardinale, R., 2006. Implicit and explicit categorization of natural scenes. Progress in Brain Research 156, 57-69.

Cuthbert, B.N., Schupp, H.T., Bradley, M.M., Birbaumer, N., Lang, P.J., 2000. Brain potentials in affective picture processing: covariation with autonomic arousal and affective report. Biol. Psychol. 52, 95-111.

Del Cul, A., Baillet, S., Dehaene, S., 2007. Brain dynamics underlying the nonlinear threshold for access to consciousness. PLoS Biol. 5, 2408-2423.

Delorme, A., Rousselet, G.A., Mace, M.J., Fabre-Thorpe, M., 2004. Interaction of top-down and bottom-up processing in the fast visual analysis of natural scenes. Cogn. Brain Res. 19, 103-113.

Delparigi, A., Chen, K., Salbe, A.D., Reiman, E.M., Tataranni, P.A., 2005. Sensory experience of food and obesity: a positron emission tomography study of the brain regions affected by tasting a liquid meal after a prolonged fast. NeuroImage $24,436-443$.

DiBattista, D., 1987. Dietary self-selection of golden hamsters in response to acute food deprivation and chronic food restriction. Behav. Neurosci. 101, 568-575.

Diehl, J.M., Staufenbiel, T., 1994. Inventar zum Essverhalten und Gewichtsproblemen (IEG). Klotz, Frankfurt.

Dobson, K.S., Dozois, D.J., 2004. Attentional biases in eating disorders: a meta-analytic review of Stroop performance. Clin. Psychol. Rev. 23, 1001-1022.

Downing, P.E., Jiang, Y., Shuman, M., Kanwisher, N., 2001. A cortical area selective for visual processing of the human body. Science 293, 2470-2473.

Drobes, D. Miller, EJ. Hillman, C.H., Bradley, M.M., Cuthbert, B.N., Lang, PJ., 2001 Food deprivation and emotional reactions to food cues: implications for eating disorders. Biol. Psychol. 57, 153-177.

Epstein, L.H., Saelens, B.E., 2000. Behavioral economics of obesity: food intake and energy expenditure. In: Bickel, W.K., Vuchinich, R.E. (Eds.), Reframing Health Behavior Change with Behavioral Economics. Erlbaum, Mahwah, NJ, pp. 293-311.

Flaisch, T., Stockburger, J., Schupp, H.T., 2008. Affective prime and target picture processing: an ERP analysis of early and late interference effects. Brain Topogr. 20 , 183-191.

Grill, H.J., Berridge, K.C. 1985. Taste reactivity as a measure of the neural control of palatability. Prog. Psychobiol. Physiol. Psychol. 11, 1-61.

Hagan, M.M., Moss, D.E., 1997. Persistence of binge-eating patterns after a history of restriction with intermittent bouts of refeeding on palatable food in rats: implications for bulimia nervosa. Int. J. Eat. Disord. 22, 411-420.

Hämäläinen, M.S., Ilmoniemi, R.J., 1994. Interpreting magnetic fields of the brain: minimum norm estimates. Med. Biol. Eng. Comput. 32, 35-42.

Hauk, O., 2004. Keep it simple: a case for using classical minimum norm estimation in the analysis of EEG and MEG data. NeuroImage 21, 1612-1621.

Herman, C.P., Polivy, J., 1980. Restrained eating. In: Stunkard, A.J. (Ed.), Obesity. Saunders, Philadelphia, pp. 208-225.

Hetherington, M.M., Stoner, S.A., Andersen, A.E., Rolls, B.J., 2000. Effects of acute food deprivation on eating behavior in eating disorders. Int. J. Eat. Disord 28, 272-283.

Hillyard, S.A., Anllo-Vento, L., 1998. Event-related brain potentials in the study of visual selective attention. Proc. Natl. Acad. Sci. U. S. A. 95, 781-787. 
Hillyard, S.A., Mangun, G.R., Woldorff, M.G., Luck, S.J., 1995. Neural systems mediating selective attention. In: Gazzaniga, M.S. (Ed.), The Cognitive Neurosciences. MIT Press, Cambridge, MA, pp. 665-681.

Hoefling, A., Strack, F., 2008. The tempting effect of forbidden foods. High calorie content evokes conflicting implicit and explicit evaluations in restrained eaters. Appetite 3, 681-689.

Junghöfer, M., Peyk, P., 2004. Analyse und Visualisierung von Hirnstrom- und Hirnmagnetfeld-Messung. Matlab. Select 2, 24-28.

Junghöfer, M., Elbert, T., Tucker, D.M., Rockstroh, B., 2000. Statistical control of artifacts in dense array EEG/MEG studies. Psychophysiology 37, 523-532.

Junghöfer, M., Bradley, M.M., Elbert, T.R., Lang, P.J., 2001. Fleeting images: a new look at early emotion discrimination. Psychophysiology 38, 175-178.

Kanwisher, N., Wojciulik, E., 2000. Visual attention: insights from brain imaging. Nat. Rev. Neurosci. 1, 91-100.

Karhunen, L.J., Lappalainen, R.I., Vanninen, E.J., Kuikka, J.T., Uusitupa, M.I., 1997. Regional cerebral blood flow during food exposure in obese and normal-weight women. Brain 120 (Pt 9), 1675-1684.

Kastner, S., Ungerleider, L.G., 2000. Mechanisms of visual attention in the human cortex. Ann. Rev. Neurosci. 23, 315-341.

Killgore, W.D., Young, A.D., Femia, L.A., Bogorodzki, P., Rogowska, J., Yurgelun-Todd, D.A., 2003. Cortical and limbic activation during viewing of high-versus low-calorie foods. Neurolmage 19, 1381-1394.

Kranczioch, C., Debener, S., Engel, A.K., 2003. Event-related potential correlates of the attentional blink phenomenon. Cogn. Brain Res. 17, 177-187.

Kringelbach, M.L., O'Doherty, J., Rolls, E.T., Andrews, C., 2003. Activation of the human orbitofrontal cortex to a liquid food stimulus is correlated with its subjective pleasantness. Cereb. Cortex 13, 1064-1071.

LaBar, K.S., Gitelman, D.R., Parrish, T.B., Kim, Y.H., Nobre, A.C., Mesulam, M.M., 2001. Hunger selectively modulates corticolimbic activation to food stimuli in humans. Behav. Neurosci. $115,493-500$.

Lang, P.J., Bradley, M.M., Cuthbert, B.N., 1997. Motivated attention: affect, activation, and action. In: Lang, P.J., Simons, R.F., Balaban, M. (Eds.), Attention and Emotion: Sensory and Motivational Processes. Erlbaum, Mahwah, NJ, pp. 97-135.

Lang, P.J., Bradley, M.M., Cuthbert, B.N., 2005. International Affective Picture System (IAPS): Digitized Photographs, Instruction Manual and Affective Ratings. Technical Report A-6. University of Florida, Gainesville, FL.

Lavy, E.H., van den Hout, M.A., 1993. Attentional bias for appetitive cues: effects of fasting in normal subjects. Behav. Cogn. Psychotherapy 21, 297-310.

Logue, A.W., King, G.R., 1991. Self-control and impulsiveness in adult humans when food is the reinforcer. Appetite 17, 105-120.

Luck, S.J, Woodman, G.F, Vogel, E.K., 2000. Event-related potential studies of attention. Trends Cogn. Sci. 4, 432-440.

Lüthy, M., Blumenthal, T.D., Langewitz, W., Kiss, A., Keller, U., Schächinger, H., 2003. Prepulse inhibition of the human startle eye blink response by visual food cues. Appetite 41, 191-195.

Margraf, J., Schneider, S., Ehlers, A., 1991. Diagnostisches Interview Bei Psychischen Störungen: DIPS. (Diagnostical Interview For Mental Disorders: DIPS). Springer, Berlin

Mauler, B.I. Hamm, A.O. Weike, A.I., Tuschen-Caffier, B., 2006. Affect regulation and food intake in bulimia nervosa: emotional responding to food cues after deprivation and subsequent eating. J. Abnorm. Psychology 115, 567-579.

Mogg, K., Bradley, B.P., Hyare, H., Lee, S., 1998. Selective attention to food-related stimuli in hunger: are attentional biases specific to emotional and psychopathological states, or are they also found in normal drive states? Behav. Res. Ther. 36, 227-237.

Morris, J.S., Dolan, R.J., 2001. Involvement of human amygdala and orbitofrontal cortex in hunger-enhanced memory for food stimuli. J. Neurosci. 21, 5304-5310.

Nieuwenhuis, S., Aston-Jones, G., Cohen, J.D., 2005. Decision making, the P3, and the locus coeruleus-norepinephrine system. Psychol. Bull. 131, 510-532.

Placanica, J.L., Faunce, G.J., Soames Job, R.F., 2002. The effect of fasting on attentional biases for food and body shape/weight words in high and low eating disorder inventory scorers. Int. J. Eat. Disord. 32, 79-90.

Posner, M.I., Petersen, S.E., 1990. The attention system of the human brain. Annu. Rev. Neurosci. 13, 25-42.
Potts, G.F., Tucker, D.M., 2001. Frontal evaluation and posterior representation in target detection. Cogn. Brain Res. 11, 147-156.

Raynor, H.A., Epstein, L.H., 2003. The relative-reinforcing value of food under differing levels of food deprivation and restriction. Appetite 40, 15-24.

Rothemund, Y., Preuschhof, C., Bohner, G., Bauknecht, H.-C., Klingebiel, R., Flor, H. Klapp, B.F. 2007. Differential activation of the dorsal striatum by high-calorie visual food stimuli in obese individuals. Neurolmage 37, 410-421.

Sabbagh, M.A., Taylor, M., 2000. Neural correlates of theory-of-mind reasoning: an event-related potential study. Psychol. Sci. 11, 46-50.

Schupp, H.T., Junghöfer, M., Weike, A.I., Hamm, A.O., 2003. Emotional facilitation of sensory processing in the visual cortex. Psychol. Sci. 14, 7-13.

Schupp, H.T., Flaisch, T., Stockburger, J., Junghöfer, M., 2006. Emotion and attention: event-related brain potential studies. Prog. Brain Res. 156, 31-51.

Schupp, H.T., Stockburger, J., Codispoti, M., Junghöfer, M., Weike, A.I., Hamm, A.O., 2007 Selective visual attention to emotion. J. Neurosci. 27, 1082-1089.

Schwarzlose, R.F., Baker, C.I., Kanwisher, N., 2005. Separate face and body selectivity on the fusiform gyrus. J. Neurosci. 25, 11055-11059.

Seibt, B., Häfner, M., Deutsch, R., 2007. Prepared to eat: how immediate affective and motivational responses to food cues are influenced by food deprivation. Eur. J. Soc. Psychol. 37, 359-379.

Sergent, C., Baillet, S., Dehaene, S., 2005. Timing of the brain events underlying access to consciousness during the attentional blink. Nat. Neurosci. 8, 1391-1400.

Siep, N., Roefs, A., Roebroeck, A., Havermans, R., Bonte, M.L., Jansen, A., 2008. Hunger is the best spice: an fMRI study of the effects of attention, hunger, calorie content on food reward processing in the amygdala and orbitofrontal cortex. Behav. Brain Res. $198,149-158$.

Simmons, W.K., Martin, A., Barsalou, L.W., 2005. Pictures of appetizing foods activate gustatory cortices for taste and reward. Cereb. Cortex 15, 1602-1608.

Sirevaag, E.J., Kramer, A.F., Coles, M.G.H., Donchin, E., 1989. Resource reciprocity - an event-related brain potential analysis. Acta Psychol. 70, 77-97.

Small, D.M., Zatorre, R.J., Dagher, A., Evans, A.C., Jones-Gotman, M., 2001. Changes in brain activity related to eating chocolate: from pleasure to aversion. Brain 124 1720-1733.

Smid, H.G., Jakob, A., Heinze, H.J., 1999. An event-related brain potential study of visual selective attention to conjunctions of color and shape. Psychophysiology 36, 264-279.

Spiegel, T.A., Shrager, E.E., Stellar, E., 1989. Responses of lean and obese subjects to preloads, deprivation, and palatability. Appetite 13, 45-69.

Stockburger, J., Weike, A. I. Hamm, A.O. Schupp, H.T 2008. Food deprivation selectively modulates brain potentials to food pictures. Behav. Neurosci. 122, 936-942.

Stockburger, J., Renner, B., Weike, A., Hamm, A.O., Schupp, H.T., 2009. Vegetarianism and food perception: selective visual attention to meat pictures. Appetite 52, 513-516.

Stoeckel, L.E. Weller, R.E., Cook III, E.W., Twieg, D.B., Knowlton, R.C. Cox, J.E. 2008. Widespread reward-system activation in obese women in response to pictures of high-calorie foods. NeuroImage 41, 636-647.

Stunkard, A.J., Messick, S., 1985. The three-factor eating questionnaire to measure dietary restraint, disinhibition and hunger. J. Psychosom. Res. 29, 71-83.

Tataranni, P.A., Gautier, J.F., Chen, K. Uecker, A Bandy, D., Salbe, A.D., Pratley, R.E. Lawson, M., Reiman, E.M., Ravussin, E., 1999. Neuroanatomical correlates of hunge and satiation in humans using positron emission tomography. Proc. Natl. Acad. Sci. U. S. A. 96, 4569-4574.

Timberlake, W., 2001. Motivational modes in behavior systems. In: Mowrer, R.R., Klein, S.B. (Eds.), Handbook of Contemporary Learning Theories. Erlbaum, Mahwah, NJ, pp. 155-209.

Toepel, U., Knebel, J.F., Hudry, J., le Coutre, J., Murray, M.M., 2009. The brain tracks the energetic value in food images. Neurolmage 44, 967-974.

Uher, R., Treasure, J., Heining, M., Brammer, M.J., Campbell, I.C., 2006. Cerebra processing of food-related stimuli: effects of fasting and gender. Behav. Brain Res. 169, 111-119.

Vogel, E.K., Luck, S.J., Shapiro, K.L., 1998. Electrophysiological evidence for a postperceptual locus of suppression during the attentional blink. J. Exp. Psychol. Hum. Percept. Perform. 24, 1656-1674. 